\title{
EFEKTIVITAS IMPLEMENTASI PROGRAM KARTU IDENTITAS ANAK
}

\section{EFFECTIVENESS OF IMPLEMENTING CHILD IDENTITY CARD PROGRAM}

\author{
Gita Ramadhanti ${ }^{*}$, Rizki Hegia Sampurna², Andi Mulyadi ${ }^{3}$ \\ 1,2,3Program Studi Administrasi Publik, Fakultas Ilmu Administrasi dan Humaniora, \\ Universitas Muhammadiyah Sukabumi, Jl. R. Syamsudin, SH No. 50, Cikole, Kota Sukabumi \\ 43113
}

*Korespondensi: Gita Ramadhanti. Email: gitarmdhnti7@gmail.com

(Diterima: 12-08-2020; Ditelaah: 16-08-2020; Disetujui: 18-08-2020)

\begin{abstract}
The Child Identity Card program has been implemented in Sukabumi City since December 2018. During December 2018 to 2020 there were 9,824 children having Child Identity Card from 105,850 children having birth certificate. There was a large gap of the numbers between children having Child Identity Card and birth certificate. The Local Office of Population and Civil Registration of Sukabumi City realizes that the implementation of Child Identity Card program does not fulfill its target yet. The aim of this research is to analyze the effectiveness of implementing the Child Identity Card program in the Local Office of Population and Civil Registration of Sukabumi City. The program effectiveness is measured by three dimensions, namely goal attainment, integrity and adaptation. The method of this research is a quantitative method combined by a descriptive approach. The research sampling uses the simple random sampling, involving 100 respondents from various different characteristics. The data collection uses questionnaires, observation and literature study. The results of this research indicate that the effectiveness of implementing the Child Identity Card program in the Local Office of Population and Civil Registration of Sukabumi City has attained a fairly effective scale. It can be concluded that the Child Identity Card program in the Local Office of Population and Civil Registration of Sukabumi City has been effectively implemented.
\end{abstract}

Key words: Program Effectiveness; Public Service; Child Identity Card Program.

\begin{abstract}
ABSTRAK
Program Kartu Identitas Anak diimplementasikan di Kota Sukabumi sejak Desember 2018. Selama Desember 2018 hingga 2020 terdapat 9.824 anak yang memiliki Kartu Identitas Anak dari 105.850 anak yang memiliki akta kelahiran. Terdapat kesenjangan jumlah yang besar antara anak yang mempunyai Kartu Identitas Anak dan akta kelahiran. Dinas Kependudukan dan Pencatatan Sipil Kota Sukabumi menyadari bahwa implementasi program Kartu Identitas Anak belum memenuhi target. Tujuan penelitian ini adalah untuk menganalisis efektivitas implementasi program Kartu Identitas Anak di Dinas Kependudukan dan Pencatatan Sipil Kota Sukabumi. Efektivitas program diukur berdasarkan tiga dimensi, yaitu pencapaian tujuan, integritas dan adaptasi. Metode yang digunakan dalam penelitian ini adalah metode kuantitatif dengan pendekatan deskriptif. Penarikan sampel menggunakan simple random sampling yang melibatkan 100 responden dari berbagai karakteristik yang berbeda. Pengumpulan data menggunakan kuesioner/angket, observasi dan studi kepustakaan. Hasil penelitian menunjukkan bahwa efektivitas implementasi program Kartu Identitas Anak di Dinas Kependudukan dan Pencatatan Sipil Kota Sukabumi telah mencapai tingkat skala yang cukup efektif. Hal ini dapat disimpulkan bahwa implementasi program Kartu Identitas Anak di Dinas Kependudukan dan Pencatatan Sipil Kota Sukabumi telah berjalan dengan efektif.
\end{abstract}

Kata kunci: Efektivitas Program; Pelayanan Publik; Program Kartu Identitas Anak.

Ramadhanti, Gita; Sampurna, Rizki Hegia \& Mulyadi, Andi. (2021). Efektivitas Implementasi Program Kartu Identitas Anak. Jurnal GOVERNANSI, 7(1): 51-58. 


\section{PENDAHULUAN}

Anak adalah setiap manusia yang berusia di bawah 18 (delapan belas) tahun dan belum menikah, termasuk anak yang masih dalam kandungan apabila hal tersebut demi kepentingannya. Salah satu hak anak adalah mendapatkan perlindungan sebagaimana termuat dalam Pasal 1 Undang-Undang Nomor 35 Tahun 2014. Dalam rangka mewujudkan upaya perlindungan hak-hak anak tersebut, maka Pemerintah Pusat menerbitkan Peraturan Menteri Dalam Negeri Nomor 2 Tahun 2016 tentang Kartu Identitas Anak. Pasal 1 ayat 7 menyatakan bahwa Kartu Identitas Anak (KIA) adalah identitas resmi anak sebagai bukti diri anak yang berusia kurang dari 17 tahun dan belum menikah yang diterbitkan oleh Dinas Kependudukan dan Pencatatan Sipil (DISDUKCAPIL) Kabupaten dan Kota. Adanya pemberian identitas kependudukan kepada anak melalui KIA dapat mendorong peningkatan pendataan, perlindungan dan pelayanan publik untuk mewujudkan hal terbaik bagi seluruh anak Indonesia.

Di Kota Sukabumi, program KIA baru dilaksanakan pada bulan Desember tahun 2018. DISDUKCAPIL Kota Sukabumi menyadari bahwa pelaksanaan program KIA belum mendapatkan hasil sebagaimana yang ditargetkan. Anak yang telah memiliki akta kelahiran berjumlah 105.850 jiwa, sedangkan anak yang memiliki KIA berjumlah 9.824 jiwa. Besarnya perbedaan jumlah antara anak yang mempunyai akta kelahiran dan KIA ini disebabkan oleh beberapa hal. Pertama, sosialisasi yang belum optimal. Selama ini, DISDUKCAPIL Kota Sukabumi hanya melakukan sosialiasi melalui media elektronik seperti radio dan program Siap Antar Jemput Bola (SIJEMPOL). Kedua, keterbatasan sarana atau fasilitas pendukung program KIA, seperti kurangnya ribbon (tinta) untuk mencetak KIA yang seharusnya diperlukan sejumlah 40.000 ribbon, tetapi jumlah yang tersedia sebanyak 25.000 ribbon. Selain itu, menurut salah seorang masyarakat pemohon KIA tidak adanya banner atau pamflet di loket maupun di papan informasi terkait SOP pembuatan KIA sehingga menyebabkan masyarakat kesulitan untuk memperoleh informasi tentang program KIA. Ketiga, pelayanan yang diberikan oleh pihak DISDUKCAPIL yang belum optimal. Di antaranya terdapat pegawai yang kurang tanggap memberikan pelayanan yang tepat waktu. Hal ini menyebabkan penumpukan antrian di loket pendaftaran.

Berdasarkan fenomena tersebut terlihat bahwa pelaksanaan program KIA belum terlaksana secara optimal. Tujuan dilakukannya penelitian ini adalah untuk menganalisis efektivitas pelaksanaan program KIA di DISDUKCAPIL Kota Sukabumi.

\section{MATERI DAN METODE}

\section{Konsep/Teori yang Relevan}

Etzioni dalam Torang (2012: 118) mengemukakan bahwa efektivitas organisasi adalah sejauhmana organisasi dapat mencapai tujuan yang diinginkan. Selain itu, Tjokroamidjojo dalam Pasolong (2017: 8) mengatakan bahwa efektivitas dilakukan supaya pelaksanaan administrasi tercapai sesuai rencana, tepat sasaran, dan tujuan serta lebih berdaya hasil.

Berdasarkan pendapat para ahli tersebut, dapat disimpulkan bahwa efektivitas merupakan pengukuran program atau kegiatan dalam mencapai tujuan dan sasaran akhir yang telah ditetapkan dalam suatu organisasi. Kata efektif sering dikaitkan dengan kata efisien. Efisien lebih mengarah kepada pemanfaatan waktu dan sumber daya yang seminimal mungkin untuk mencapai tujuan. Sedangkan efektif lebih mengacu pada tujuan dan sasaran organisasi, sehingga sesuatu yang efisien belum tentu efektif.

Duncan dalam Steers (1985: 53) mengemukakan bahwa ukuran efektivitas dalam pengukuran efektivitas program terdiri dari tiga dimensi. Pertama, pencapaian tujuan. Keseluruhan upaya 
pencapaian tujuan harus dipandang sebagai suatu proses. Oleh karena itu, agar pencapaian tujuan akhir semakin terjamin, diperlukan pentahapan, baik dalam arti pentahapan pencapaian bagian-bagiannya maupun pentahapan dalam arti periodisasinya. Pencapaian tujuan terdiri dari indikator, yaitu kurun waktu pencapaian yang ditentukan dan pencapaian sasaran yang merupakan target konkrit. Kedua, integritas, yaitu pengukuran terhadap tingkat kemampuan suatu organisasi untuk melakukan kegiatan dari program kerja yang telah disepakati dan mengadakan sosialisasi dengan pihak lain. Integritas terdiri dari indikator, yaitu prosedur dan proses sosialisasi. Ketiga, adaptasi, yaitu kemampuan organisasi untuk menyesuaikan diri dengan lingkungannya. Adaptasi terdiri dari indikator, yaitu peningkatan kemampuan dan sarana prasarana.

\section{Metode}

Metode yang digunakan dalam penelitian ini adalah metode kuantitatif dengan pendekatan deskriptif. Populasi dalam penelitian ini adalah masyarakat Kota Sukabumi yakni orangtua. Penarikan sampel menggunakan simple random sampling, yaitu teknik pengambilan sampel secara acak tanpa memperhatikan strata atau tingkatan anggota populasi tersebut (Sugiyono, 2018: 82). Jumlah sampel sebanyak 100 sampel yang dijadikan sebagai responden penelitian. Pengumpulan data menggunakan kuesioner/ angket, observasi dan studi kepustakaan. Penelitian ini menggunakan pengukuran skala Likert. Menurut Sugiyono (2018: 93), skala Likert digunakan untuk mengukur sikap, pendapat, dan persepsi seseorang atau sekelompok orang tentang fenomena sosial.

Hipotesis penelitian dirumuskan sebagai berikut: $\mathrm{H}_{0}$ : Implementasi program KIA dinyatakan tidak efektif. $\mathrm{H}_{1}$ : Implementasi program KIA dinyatakan efektif. Uji hipotesis menggunakan uji satu sampel ttest (one sampel t-test) yang digunakan untuk menguji hipotesis deskriptif satu atau lebih variabel yang datanya berbentuk interval atau rasio. Untuk mengetahui tingkat validitas, peneliti menggunakan metode Korelasi Pearson Product Moment yang menyatakan item pertanyaan dinyatakan valid apabila $r_{\text {hitung }}>r_{\text {tabel }}$ dan begitu pula sebaliknya. Hasil pengukuran dapat dipercaya apabila beberapa kali pelaksanaan pengukuran terhadap kelompok subjek yang sama diperoleh hasil relatif yang sama. Uji reliabilitas menggunakan metode Cronbach Alpha, jika nilai Cronbach alpha $>r_{\text {tabel }}$ sebesar 0,7 maka instrumen dikatakan reliabel, handal atau konsiten.

\section{HASIL DAN PEMBAHASAN}

Undang-Undang Nomor 24 Tahun 2013 tentang Administrasi Kependudukan, Pasal 1 ayat 1 , menyatakan bahwa administrasi kependudukan adalah rangkaian kegiatan penataan dan penertiban dalam penerbitan dokumen dan data kependudukan melalui pendaftaran penduduk. Undang-Undang Nomor 24 Tahun 2013 tentang Administrasi Kependudukan, Pasal 8, menyatakan bahwa instansi pelaksana, adalah DISDUKCAPIL.

DISDUKCAPIL Kota Sukabumi adalah lembaga pemerintahan yang melaksanakan pendaftaran dan pencatatan penduduk yang memiliki tugas utama untuk membantu kepala daerah dalam melaksanakan sebagian urusan pemerintahan dan pembangunan di bidang kependudukan dan pencatatan sipil, salah satunya mengenai pelaksanaan program KIA.

Untuk mengetahui implementasi program KIA, kuesioner dalam penelitian ini disebarkan kepada pemohon yang sudah pernah mengurus program KIA di DISDUKCAPIL Kota Sukabumi dengan jumlah sampel sebanyak 100 orang. Peneliti menjelaskan tanggapan responden mengenai variabel efektivitas implementasi program KIA di DISDUKCAPIL Kota Sukabumi berdasarkan teori Duncan dalam Steers (1985: 53) yang mencakup tiga 
dimensi, yaitu pencapaian tujuan, integritas dan adaptasi. Secara keseluruhan skor dan kumulatif untuk masing-masing pernyataan efektivitas implementasi program KIA dapat dilihat pada diagram persentase jawaban responden untuk masing-masing item instrumen pada variabel efektivitas implementasi program KIA di bawah ini.

\section{Uji Instrumen Penelitian}

\section{a. Uji Validitas}

Uji validitas dalam penelitian ini menggunakan metode Pearson Product Moment dengan program SPSS versi 26. Keputusan pada sebuah item pertanyaan dapat dianggap valid apabila $r_{\text {hitung }}$ (Koefisien Korelasi Pearson) $>r_{\text {tabel }}$ 0,30. Untuk mengetahui item pernyataan angket pada variabel efektivitas implementasi program KIA dinyatakan valid atau tidak valid disajikan pada Tabel 1.

Tabel 1. Hasil Perhitungan Pengujian Validitas Item Efektivitas Program KIA

\begin{tabular}{cccc}
\hline $\begin{array}{c}\text { No } \\
\text { Item }\end{array}$ & rhitung & rtabel & Validitas \\
\hline 1 & 0,42 & 0,30 & Valid \\
\hline 2 & 0,38 & 0,30 & Valid \\
\hline 3 & 0,47 & 0,30 & Valid \\
\hline 4 & 0,51 & 0,30 & Valid \\
\hline 5 & 0,38 & 0,30 & Valid \\
\hline 6 & 0,50 & 0,30 & Valid \\
\hline 7 & 0,35 & 0,30 & Valid \\
\hline 8 & 0,40 & 0,30 & Valid \\
\hline 9 & 0,40 & 0,30 & Valid \\
\hline 10 & 0,33 & 0,30 & Valid \\
\hline 11 & 0,43 & 0,30 & Valid \\
\hline 12 & 0,44 & 0,30 & Valid \\
\hline 13 & 0,42 & 0,30 & Valid \\
\hline 14 & 0,33 & 0,30 & Valid \\
\hline 15 & 0,34 & 0,30 & Valid \\
\hline 16 & 0,36 & 0,30 & Valid \\
\hline 17 & 0,48 & 0,30 & Valid \\
\hline 18 & 0,34 & 0,30 & Valid \\
\hline 19 & 0,31 & 0,30 & Valid \\
\hline 20 & 0,37 & 0,30 & Valid \\
\hline 21 & 0,45 & 0,30 & Valid \\
\hline
\end{tabular}

Sumber: Hasil Olahan Kuesioner Penelitian (2020)

Berdasarkan hasil Tabel 1 maka dapat dinyatakan bahwa seluruh item instrumen efektivitas program KIA valid, karena pada setiap butir di atas nilai $r_{\text {hitung }}$ melebihi dari $r_{\text {tabel }}$ yaitu 0,30 . Pada tabel di atas, item yang memiliki nilai validitas tertinggi terdapat pada nomor 4 dengan nilai sebesar 0,51 , sedangkan item yang memiliki validitas rendah terdapat pada item nomor 19 dengan nilai 0,31 .

\section{b. Uji Reliabilitas}

Pengujian reliabilitas dilakukan dengan internal konsistensi menggunakan Cronbach alpha. Jika nilai Cronbach alpha > 0,70 maka instrumen dikatakan reliabel. Hasil pengujian reliabilitas instrumen penelitian atau angket variabel efektivitas implementasi program KIA disajikan pada Tabel 2.

Tabel 2. Uji Reliabilitas Variabel Efektivitas Program KIA

\begin{tabular}{cr}
\hline \multicolumn{2}{c}{ Reliability Statistics } \\
\hline Cronbach's Alpha & N of Items \\
\hline .810 & 21 \\
\hline
\end{tabular}

Sumber: Hasil Olahan Kuesioner Penelitian (2020)

Berdasarkan Tabel 2, diketahui nilai Cronbach alpha memperoleh nilai sebesar 0,810 . Skor tersebut berada di atas $r$ kritis 0,70 sehingga dapat dinyatakan reliabel, handal, atau konsisten dalam pengukuran.

\section{Tanggapan Responden Mengenai Variabel Efektivitas Implementasi Program KIA}

\section{a. Dimensi Pencapaian Tujuan}

Pencapaian tujuan menunjukkan keseluruhan upaya pencapaian tujuan harus dipandang sebagai suatu proses. Oleh karena itu, agar pencapaian tujuan akhir semakin terjamin, diperlukan pentahapan, baik dalam arti pentahapan pencapaian bagian-bagiannya maupun pentahapan dalam arti periodisasinya. Untuk mengetahui tanggapan mengenai tujuan program KIA ditetapkan secara formal dan tertulis dapat dilihat dari Diagram 1. 
Diagram 1. Persentase Rata-rata Jawaban Responden Dimensi Pencapaian Tujuan

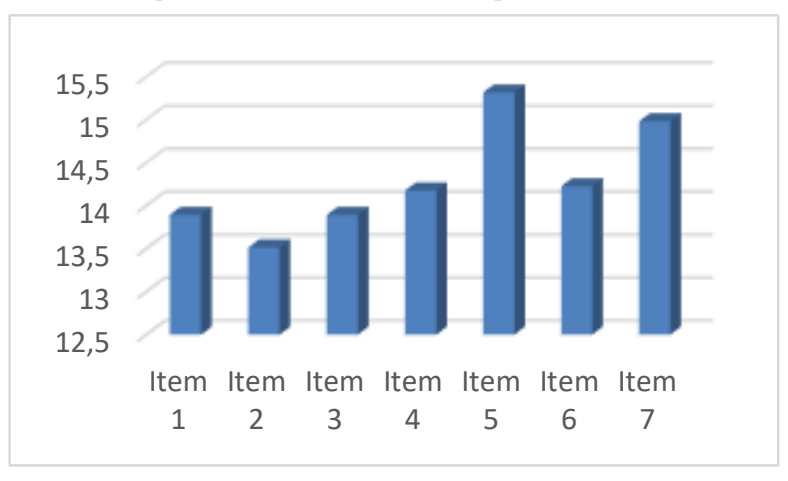

Sumber: Hasil Olahan Kuesioner Penelitian (2020)

\section{b. Dimensi Integritas}

Integritas mengukur tingkat kemampuan organisasi untuk melakukan kegiatan dari program kerja yang telah disepakati dan mengadakan sosialisasi dengan pihak lain. Untuk mengetahui tanggapan responden mengenai usaha pelaksana KIA telah maksimal dalam menjalin hubungan dengan sekolah-sekolah untuk memudahkan pendataan KIA dapat dilihat dari Diagram 2.

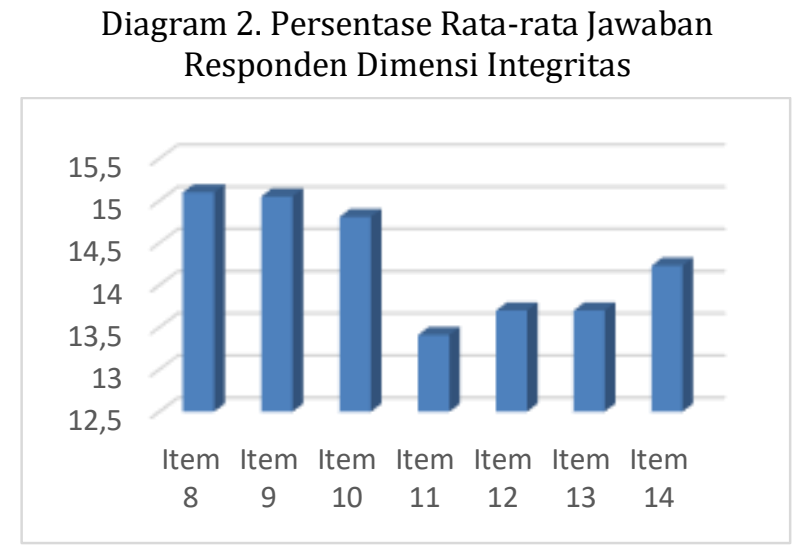

Sumber: Hasil Olahan Kuesioner Penelitian (2020)

\section{c. Dimensi Adaptasi}

Adaptasi menggambarkan kemampuan organisasi untuk menyesuaikan diri dengan lingkungannya. Untuk mengetahui tanggapan responden mengenai sarana yang tersedia di DISDUKCAPIL Kota Sukabumi telah sesuai dengan yang dibutuhkan program KIA dapat dilihat dari Diagram 3.
Diagram 3. Persentase Rata-rata Jawaban Responden Dimensi Adaptasi

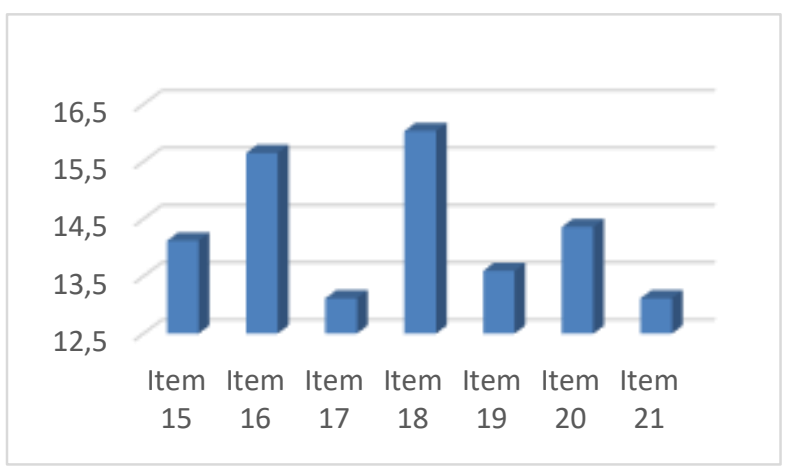

Sumber: Hasil Olahan Kuesioner Penelitian (2020)

Berdasarkan Diagram 1, 2 dan 3 di atas, total skor tertinggi terdapat pada item 18 dimensi adaptasi mengenai indikator kerjasama DISDUKCAPIL dengan pihak ketiga sebagai mitra dalam memberikan nilai tambah dan memaksimalkan program KIA dengan total skor 335. Sedangkan total skor terendah pada item 17 dan 21 dimensi adaptasi mengenai indikator strategi DISDUKCAPIL dalam memaksimalkan penerbitan program KIA dan indikator blanko KIA untuk mencukupi kebutuhan permohonan dengan total skor 274 .

Hasil dari perhitungan variabel efektivitas berdasarkan jawaban-jawaban responden secara keseluruhan mendapat skor sebesar 6.271 untuk mengetahui tinggi rendahnya variabel efektivitas adalah sebagai berikut:

\begin{tabular}{ll}
\hline Skor yang dicapai & x 100 \\
\hline Skor yang diharapkan & \\
\hline 6.271 & \\
\hline 10.500 & \\
\hline$=59,72 \%$ & \\
\hline
\end{tabular}

Tabel 3. Skala dan Klasifikasi Pengukuran Efektivitas Pelaksanaan Program KIA

\begin{tabular}{clc}
\hline No. & Pengukuran Efektivitas & Kriteria (\%) \\
\hline 1 & Sangat Tidak Efektif & $\leq 20$ \\
\hline 2 & Tidak Efektif & $21-40$ \\
\hline 3 & Cukup Efektif & $41-60$ \\
\hline 4 & Efektif & $61-80$ \\
\hline 5 & Sangat Efektif & $81-100$ \\
\hline
\end{tabular}

Sumber: Sugiyono (2017: 214) 
Berdasarkan perhitungan skala dan klasifikasi pengukuran efektivitas implementasi program KIA berjumlah 59,72\% yang dapat dilihat pada Tabel 3 berada di tingkat yang cukup efektif.

\section{Uji Hipotesis}

Pengujian hipotesis menggunakan satu sampel $t$-test (one sample test) dengan nilai alpha sebesar $5 \%(0,05)$. Hasil uji satu sampel t-test (one sample test) dengan menggunakan program SPSS versi 26 dengan tingkat signifikan sebesar 0,05 (5\%) menunjukkan bahwa variabel efektivitas sebesar 67.222. Nilai dari thitung dibandingkan dengan nilai $t_{\text {tabel. }} t_{\text {tabel }}$ dicari pada tabel dengan didasarkan pada $\mathrm{dk}=(\mathrm{n}-\mathrm{k}-1)$ dan taraf kesalahan yang ditetapkan sebesar $5 \%$, jadi $\mathrm{dk}=100-2-1=97$ sehingga diperoleh $t_{\text {tabel }}=1.66071$. Berdasarkan hasil dari tabel di atas dapat dilihat bahwa nilai $t_{\text {hitung }}$ lebih besar daripada $t_{\text {tabel }}$ dimana nilai $t_{\text {hitung }} 67.222>t_{\text {tabel }} 1.66071$ maka $\mathrm{H}_{0}$ ditolak dan $\mathrm{H}_{1}$ diterima. Hal ini menunjukkan bahwa efektivitas pelaksanaan program KIA di DISDUKCAPIL Kota Sukabumi dinyatakan efektif.

Pencapaian tujuan menunjukkan keseluruhan upaya yang harus dipandang sebagai suatu proses. Oleh karena itu, agar pencapaian tujuan akhir semakin terjamin, diperlukan pentahapan, baik dalam arti pentahapan pencapaian bagian-bagiannya maupun pentahapan dalam arti periodisasinya. DISDUKCAPIL Kota Sukabumi dalam pelaksanaan program KIA memperoleh tingkat keberhasilan dimensi pencapaian tujuan sebesar 20,09\%, dimana perolehan nilai indikator tertinggi pada dimensi ini terdapat pada indikator pelaksana program KIA memenuhi kriteria untuk dinyatakan memiliki keterampilan kerja, dan perolehan nilai indikator terendah pada dimensi ini terdapat pada indikator tujuan program KIA tidak berbenturan dengan tujuan program akta kelahiran.
Integritas mengukur tingkat kemampuan organisasi untuk melakukan kegiatan dari program kerja yang telah disepakati dan mengadakan sosialisasi dengan pihak lain. Dalam pelaksanaan program KIA, DISDUKCAPIL Kota Sukabumi memperoleh tingkat keberhasilan dimensi integritas sebesar 19,74\%, dimana perolehan nilai tertinggi pada dimensi ini terdapat pada indikator pelaksana KIA telah maksimal dalam menjalin hubungan dengan sekolahsekolah dalam memudahkan pendataan KIA. Sedangkan perolehan nilai terendah pada dimensi ini terdapat pada indikator hubungan pelaksana KIA dengan pelaksana akta kelahiran dalam memudahkan proses pendataan KIA.

Adaptasi menggambarkan kemampuan organisasi untuk menyesuaikan diri dengan lingkungannya. DISDUKCAPIL Kota Sukabumi dalam pelaksanaan program KIA memperoleh tingkat keberhasilan dimensi adaptasi sebesar 19,90\%, dimana perolehan nilai tertinggi pada dimensi ini terdapat pada indikator kerjasama DISDUKCAPIL dengan pihak ketiga sebagai mitra dalam memberikan nilai tambah dan memaksimalkan program KIA. Sedangkan nilai terendah pada dimensi ini terdapat pada indikator strategi DISDUKCAPIL dalam memaksimalkan penerbitan program KIA dan penyediaan blanko KIA untuk mencukupi kebutuhan permohonan.

Dari ketiga dimensi di atas, hasil yang diperoleh dalam penelitian ini sebesar 59,72\%. Efektivitas pelaksanaan program KIA di DISDUKCAPIL Kota Sukabumi dapat dinyatakan cukup efektif. Hal tersebut diperkuat dengan penilaian responden selaku pemohon pelayanan dalam penerbitan KIA yang menyatakan efektivitas program KIA dalam kategori penilaian yang cukup baik. Meski responden penelitian memberikan penilaian bahwa program KIA yang dilaksanakan oleh DISDUKCAPIL Kota Sukabumi sudah cukup efektif, namun terdapat hal-hal yang dirasakan perlu untuk ditingkatkan kembali. 


\section{KESIMPULAN DAN REKOMENDASI}

\section{Kesimpulan}

Berdasarkan hasil dan pembahasan, maka penelitian ini menunjukkan bahwa efektivitas pelaksanaan program KIA di DISDUKCAPIL Kota Sukabumi mencapai tingkat skala yang cukup efektif. Hal ini dapat disimpulkan bahwa implementasi program KIA di DISDUKCAPIL Kota Sukabumi sudah berjalan dengan efektif. Akan tetapi dalam implementasi program tersebut, kendala yang masih dihadapi terutama berkaitan dengan kurang tersedianya sarana, khususnya blanko KIA.

\section{Rekomendasi}

Berdasarkan kesimpulan tersebut, maka penelitian ini merekomendasikan halhal sebagai berikut:

1. DISDUKCAPIL melakukan sosialisasi program KIA dengan menggunakan berbagai media seperti memberikan tugas secara resmi kepada pemerintah daerah baik kecamatan ataupun kelurahan untuk mensosialisasikan kepada masyarakat sehingga dapat meningkatkan pengetahuan dan kesadaran masyarakat mengenai program KIA.

2. DISDUKCAPIL melengkapi sarana dan prasarana untuk pembuatan KIA berupa penambahan ribbon ataupun banner tentang KIA agar dapat memberikan kemudahan bagi masyarakat yang akan membuat KIA. Termasuk penyediaan blanko KIA.

3. DISDUKCAPIL mengoptimalkan pelayanan, terutama pelayanan tepat waktu, sehingga masyarakat dapat merasakan kepuasan pelayanan yang diberikan.

\section{DAFTAR PUSTAKA}

\section{Buku}

Dunn, William N. (2002). Pengantar Analisis Kebijakan Publik. Yogyakarta: Gadjah Mada University Press.
Mahsun, Mohamad. (2006). Pengukuran Kinerja Sektor Publik. Cetakan Pertama. Yogyakarta: Penerbit BPFEYogyakarta.

Pasolong, Harbani. (2013). Teori Administrasi Publik. Bandung: Alfabeta.

Riduwan. (2005). Skala Pengukuran Variabel-variabel Penelitian. Bandung: Afabeta.

Silalahi, Ulber. (2017). Metode Penelitian Sosial Kuantitatif. Bandung: PT. Refika Aditama.

Steers, M. Richard. (1985). Efektivitas Organisasi. Jakarta: Erlangga.

Sugiyono. (2018). Metode Penelitian Kuantitatif, Kualitatif, dan R\&D. Bandung: Alfabeta.

Sulistiyani, Sony. (2003). Ekonomi Sumber Daya Manusia: Konsep, Teori dan Pengembangan dalam Konteks Organisasi Publik. Edisi Kedua. Yogyakarta: Graha Ilmu.

Sutrisno, Edy. (2010). Budaya Organisasi. Jakarta: Prenadamedia Group.

Sutarto. (2012). Dasar-dasar Organisasi. Yogyakarta: Gadjah Mada University Press.

Torang, Syamsir. (2012). Metode Riset Struktur \& Perilaku Organisasi. Bandung: Alfabeta.

\section{Jurnal}

Arista, Windi Dwi \& Suderana, Wayan. (2019). "Implementasi Kebijakan Program Kartu Identitas Anak (KIA) di Dinas Kependudukan dan Catatan Sipil Kabupaten Badung". Jurnal Ilmiah Dinamika Sosial, 3(1): 56-66. https://doi.org/10.38043/jids.v3i1.1 733.

Permana, Jaka; Hamid, Abdul \& Nugroho, Kandung Sapto. (2018). Evaluasi Program Kartu Identitas Anak (KIA) Di Kota Cilegon Tahun 2018. Program Studi Administrasi Publik, Fakultas Ilmu Sosial dan Ilmu Politik, 
Universitas Sultan Ageng Tirtayasa. http://ap.fisip-untirta.ac.id.

Rahmawati, Linda; Agustino, Leo \& Ismanto, Gandung. (2018). Efektivitas Pelaksanaan Program Kartu Identitas Anak (KIA) di Dinas Kependudukan dan Catatan Sipil Kota Cilegon Tahun 2017. Program Studi Administrasi Publik, Fakultas Ilmu Sosial dan Ilmu Politik, Universitas Sultan Ageng Tirtayasa. http://ap.fisip-untirta.ac.id.

\section{Peraturan Perundang-undangan}

Peraturan Menteri Dalam Negeri Nomor 2 Tahun 2016 tentang Kartu Identitas Anak (Berita Negara Republik Indonesia Tahun 2016 Nomor 80).

Peraturan Walikota Sukabumi Nomor 41 Tahun 2016 tentang Kedudukan, Susunan Organisasi, Tugas Pokok, Fungsi, dan Tata Kerja Dinas Kependudukan dan Pencatatan Sipil (Berita Daerah Kota Sukabumi Tahun 2016 Nomor 41).

Undang-Undang Republik Indonesia Nomor 25 Tahun 2009 tentang Pelayanan Publik (Lembaran Negara Republik Indonesia Tahun 2009 Nomor 112, Tambahan Lembaran Negara Republik Indonesia Nomor 5038).

Undang-Undang Republik Indonesia Nomor 24 Tahun 2013 tentang Perubahan Atas Undang-Undang Nomor 23 Tahun 2006 Tentang Administrasi Kependudukan (Lembaran Negara Republik Indonesia Tahun 2013 Nomor 232, Tambahan Lembaran Negara Republik Indonesia Nomor 5475).

Undang-Undang Republik Indonesia Nomor 35 Tahun 2014 tentang Perubahan atas Undang-Undang Nomor 23 Tahun 2002 Tentang Perlindungan Anak (Lembaran Negara Republik Indonesia Tahun 2014 Nomor 297, Tambahan Lembaran Negara Republik Indonesia Nomor 5606).

\section{Laman}

Disdukcapil. 2020. Retrieved from http:// disdukcapil.sukabumikota.go.id/tenta ng-kami.

Lapor. (2019). Retrieved from http://kkp. lapor.go.id/instansi/dinaskependudukan-dan-pencatatan-sipilkota-sukabumi. 